\title{
Hubungan antara Pengetahuan Remaja tentang Kesehatan Reproduksi dengan Pernikahan Dini di Desa Panggung Kecamatan Sampang, Sampang
}

\author{
Yuni Khoirul Waroh \\ Prodi DIII Kebidanan Fakutas IImu Kesehatan Universitas PGRI Adi Buana Surabaya \\ *corresponding author \\ Yuni Khoirul Waroh \\ yunikhoirulwaroh@unipasby.ac.id
}

\begin{abstract}
Abstrak
Pernikahan dini adalah bentuk tindakan kekerasan kepada anak yang berakibat pada pendidikan, ekonomi dan kesehatan pelaku. Berdasarkan Susenas 2008-2018 didapatkan data bahwa di Indonesia ada lebih dari satu juta perempuan dengan usia 20-24 tahun yang perkawinan pertamanya terjadi di usia kurang dari 18 tahun (1,2 juta jiwa), dan perempuan yang usia 20-24 tahun melangsungkan pernikahan pertama sebelum berusia 15 tahun sebanyak 61,3 ribu jiwa. Menurut data Badan Pusat Statistik Jawa Timur tahun 2016 didapatkan data sebanyak 21, $16 \%$ perempuan usia 10 tahun ke atas yang kawin di bawah umur (kurang dari 17 tahun), sedangkan di Sampang didapatkan sebanyak 35, 37\% anak perempuan usia 10 tahun ke atas yang kawin di bawah umur (kurang dari 17 tahun).Tujuan penelitian ini adalah untuk menganalisa hubungan pengetahuan remaja tentang kesehatan reproduksi terhadap pernikahan dini yang bisa berakibat pada kesehatan reproduksi antara lain: kehamilan pada perempuan usia dini berakibat pada kematian ibu dan janinnya, kelainan kongenital, kelahiran prematur, pre eklampsia, berat badan lahir rendah, penyakit menular seksual, dan depresi postpartum. Penelitian ini menggunakan survei analitik cross sectional. Populasi dalam penelitian ini sebanyak 65 orang remaja di Dusun Panggung Desa Panggung Kecamatan Sampang, Sampang. Besar sampel dalam penelitian ini sejumlah 30 orang. Pengambilan sampel dilakukan dengan teknik simple random sampling. Penelitian dilaksanakan pada bulan November 2019 - Februari 2020. Instrumen yang digunakan dalam penelitian ini adalah kuesioner dan Kartu Tanda Penduduk. Uji statistik pada penelitian ini menggunakan Chi-square, dan didapatkan nilai $p=0.006$ sehingga $p<\alpha$. Maka dapat disimpulkan ada hubungan antara pengetahuan remaja tentang kesehatan reproduksi dengan pernikahan dini di Desa Panggung Kecamatan Sampang, Sampang.
\end{abstract}

Kata kunci: Pengetahuan; Pernikahan Dini; Kesehatan Reproduksi; Remaja 


\title{
The Relationship Between Adolescent Knowledge About Reproductive Health with Early Marriage in Panggung Village, Sampang Sub-District, Sampang
}

\begin{abstract}
Early marriage is a form of violence against children that results in the education, economy and health of the offender. Based on the 2008-2018 National Socioeconomic Survey, data obtained that in Indonesia, more than one million women aged 20-24 years, their first marriage occurred at the age of less than 18 years (1.2 million people), and women aged 20-24 years who entered into their first marriage before the age of 15 years as many as 61.3 thousand inhabitants. According to data from the Central Statistics Agency for East Java in 2016 there were 21, 16\% of women aged 10 years and over who were married underage (less than 17 years), while in Sampang there were 35, 37\% of girls aged 10 years and over underage marriage (less than 17 years). The purpose of this study is to analyze the relationship of adolescent knowledge about reproductive health to early marriage in Panggung Village, Sampang District, Sampang, which can have an impact on reproductive health, among others: pregnancy in young women resulting in maternal and fetal death, congenital abnormalities, premature birth, pre-eclampsia, low birth weight, sexually transmitted diseases, and postpartum depression. This study uses a cross sectional analytic survey. The population in this study were 65 teenagers in Panggung Village, Panggung Village, Sampang District, Sampang. The sample size was 30 people. The sampling technique was carried out by random sampling. The research was conducted in November 2019 - February 2020. The instruments used in this study were questionnaires and Identity Cards. The statistical test in this study uses Chi-square and the results obtained $p=0.006$ so that $p<\alpha$. Then it can be concluded there is a relationship between adolescent knowledge about reproductive health with early marriage in the Panggung Village Sampang sub-district, Sampang.
\end{abstract}

Keyword: Knowledge; Early Marriage; Reproduction Health; Teenager

Pendahuluan

Kesehatan reproduksi dan
seksual pada remaja perlu
mendapatkan perhatian khusus,
mengingat Indonesia pada saat ini
mengalami puncak demografi, dan
ketika tidak tertangani akan
mengakibatkan dampak jangka
panjang pada keberlangsungan
bangsa (jatim.bps.go.id).

Remaja yang di mana merupakan fase peralihan antar fase anak-anak ke dewasa memiliki berbagai riressiko terutama berkaitan dengan organ genetalianya, yang apabila kurang pengarahan dari orangtua dan juga lingkungan akan berakibat pada kenakalan remaja, putus sekolah, pergaulan bebas yang juga bisa berujung pada 
Hubungan antara Pengetahuan Remaja tentang Kesehatan Reproduksi dengan Pernikahan Dini di Desa Panggung Kecamatan Sampang, Sampang

pernikakahan di usia muda, postpartum (Kabir, Ghosh and perdagangan manusia (human Shawly, 2019)

trafficking), dan lain-lain (jatim.bps.go.id).

Pada tahun 2018, terdapat 1.220.900 anak gadis usia 20-24 tahun yang berumahtangga sebelum berusia 18 tahun, dan ini membuat urutan Indonesia masuk top 10 negara yang terdapat pernikahan dini di dunia (Kementerian PPN/Bappenas, 2020).

Perkawinan pada usia dini merupakan salah satu pelanggaran terhadap hak anak. Anak yang karena keadaan harus memulai komitmen berumahtangga pada saat berusia kurang dari 18 tahun akan mendapatkan risiko, antara lain terputusnya cita-cita untuk bersekolah, berpotensi menjadi korban kekerasan seksual, dan hidup pada taraf ekomonomi pra sejahtera (Kementerian PPN/Bappenas, 2020).

Pernikahan dini bisa berakibat pada kesehatan reproduksi antara lain: kehamilan pada perempuan usia dini berakibat pada kematian ibu dan janinnya, kelainan kongenital, kelahiran prematur, preeklampsia, berat badan lahir rendah, penyakit menular seksual, dan depresi

Lebih dari 1 juta anak perempuan telah melakukan pernikahan dini. Ada 3 provinsi yang paling tinggi dalam kejadian pernikahan dini,dan ketiganya berada di Pulau Jawa (Kementerian PPN/ Bappenas, 2020).

Berdasarkan statistik, perempuan Jawa Timur yang melakukan pernikahan di usia tidak lebih dari 15 tahun pada tahun 2018 sebanyak 4,26 \% (jatim.bps.go.id, 2018).

Fenomena yang terjadi pada masyarakat khususnya di daerah Sampang, didapatkan minimal 79 orang siswa SMP dari beberapa sekolah di Kabupaten Sampang, Jawa Timur berhenti sekolah (drop out), dikarenakan menikah diusia dini. (Republika.co.id, 2020)

Jumlah perempuan di Sampang usia 10 tahun ke atas yang menikah dini (kurang dari 17 tahun) tahun 2016 sebanyak 35, 37\% (Badan Pusat Statistik Jawa Timur, 2017).

\section{Metode}

Penelitian ini dilakukan dengan survei analitik cross sectional. Jumlah populasi yang ada dalam penelitian 
Hubungan antara Pengetahuan Remaja tentang Kesehatan Reproduksi dengan Pernikahan Dini di Desa Panggung Kecamatan Sampang, Sampang

adalah 65 remaja. Penelitian dilaksanakan pada bulan November 2019-Februari 2020.

Simple random sampling adalah cara yang digunakan dalam pengambilan sampel penelitian. Pengambilan data ini dilakukan dengan menggunakan sampel sejumlah 30 orang yang memenuhi kriteria, antara lain:

1. Laki-laki yang berumur 10-19 tahun.

2. Perempuan yang berusia 10-16 tahun.

3. Bersedia menjadi responden.

Instrumen yang digunakan adalah kuesioner tentang pengetahuan tentang kesehatan reproduksi dan Kartu Tanda Penduduk. Uji statistik pada penelitian ini menggunakan Chisquare.

\section{Hasil dan Pembahasan}

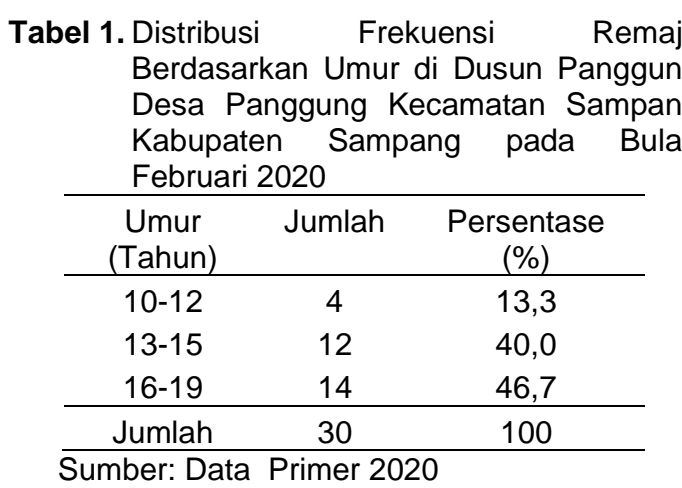

Tabel 1 menggambarkan dari 30 remaja didapat sebagian kecil berumur 10-12 tahun sebanyak 4 remaja $(13,3 \%)$, berumur $13-15$ sebanyak 12 remaja (40\%), dan berumur 16-19 tahun sebanyak 14 remaja $(46,7 \%)$.

Umur sangat berperan penting dalam memperoleh pengetahuan sekaligus dalam pengambilan keputusan. Semakin matang umur seseorang fungsi organ-organ tubuhnya juga mengalami peningkatan termasuk daya ingat. Hal ini sejalan dengan penelitian $\mathrm{Md}$. Ruhul Kabir, Susmita Ghosh and Asma Shawly (2019) yang menyatakan terdapat hubungan umur dengan kesehatan reproduksi yang sangat erat, apabila terjadi kehamilan pada perempuan di usia dini yang di mana anatomi tubuh belum siap untuk proses kehamilan, yang berakibat pada kematian pada ibu dan anak selama proses kehamilan maupun persalinan, kelahiran prematur, berat bayi lahir kurang 2500 gram, kelainan bawaan, sexually transmitted diseases, depresi postpartum.

Menurut UNICEF (2019) ibu berumur kurang dari 20 tahun akan memiliki risiko sekitar 2 kali lipat yang berakibat pada kematian pada anak yang dilahirkan selama 28 hari 
Hubungan antara Pengetahuan Remaja tentang Kesehatan Reproduksi dengan Pernikahan Dini di Desa Panggung Kecamatan Sampang, Sampang

pertama kehidupan daripada ibu berusia 20-29 tahun Berdasarkan Pendidikan di Dusun Panggung Desa Panggung Kecamatan Sampang Kabupaten Sampang pada Bulan Februari 2020

\begin{tabular}{lcc}
\hline Pendidikan & Jumlah & $\begin{array}{c}\text { Persentase } \\
(\%)\end{array}$ \\
\hline SD & 9 & 30,0 \\
SMP & 13 & 43,3 \\
SMA & 8 & 26,7 \\
Perguruan & 0 & 0 \\
Tinggi & 30 & 100 \\
\hline \multicolumn{1}{c}{ Jumlah } &
\end{tabular}

Sumber : Data Primer 2020

Tabel 2 menggambarkan dari 30 remaja didapat yang berpendidikan SD sebanyak 9 remaja (30\%), hampir setengahnya berpendidikan SMP sebanyak 13 remaja (43,3\%), berpendidikan SMA sebanyak 8 remaja $(26,7 \%)$ dan tidak ada yang berpendidikan Perguruan Tinggi $(0 \%)$.

Berdasarkan teori, semakin tingginya pendidikan seseorang, maka semakin berkembang tingkat pengetahuan yang pada akhirnya terimplementasi pada sikap dan perilaku. Hasil ini sejalan dengan penelitian Desiyanti (2015) dan Hotchkiss et.al. (2016) yang menarik kesimpulan ada hubungan antara tingkat pendidikan dengan pernikahan dini.
Tabel 3 Distribusi Frekuensi Remaja Berdasarkan Jenis Kelamin di Dusun Panggung Desa Panggung Kecamatan Sampang Kabupaten Sampang pada Bulan April 2020

\begin{tabular}{ccc}
\hline Jenis Kelamin & Jumlah & $\begin{array}{c}\text { Persentase } \\
(\%)\end{array}$ \\
\hline Laki-laki & 17 & 56,7 \\
Perempuan & 13 & 43,3 \\
\hline Jumlah & 30 & 100 \\
\hline Sumber: Data Primer 2020 &
\end{tabular}

Tabel 3 menunjukkan dari 30 remaja sebagian besar berjenis kelamin laki-laki dengan jumlah 17 remaja $(56,7 \%)$ dan hampir setengahnya berjenis kelamin perempuan dengan jumlah 13 remaja (33,3\%).

Penelitian Credos Institute (2017), menjelaskan bagaimana peran sosialisasi gender dapat mempengaruhi masyarakat untuk pernikahan dini. Perempuan dianggap siap untuk menikah adalah seseorang yang bisa mengurus rumah tangga, sementara untuk lakilaki mandiri secara ekonomi untuk memenuhi kebutuhan rumah tangga saja, tanpa mengindahkan kesiapan yang lain.

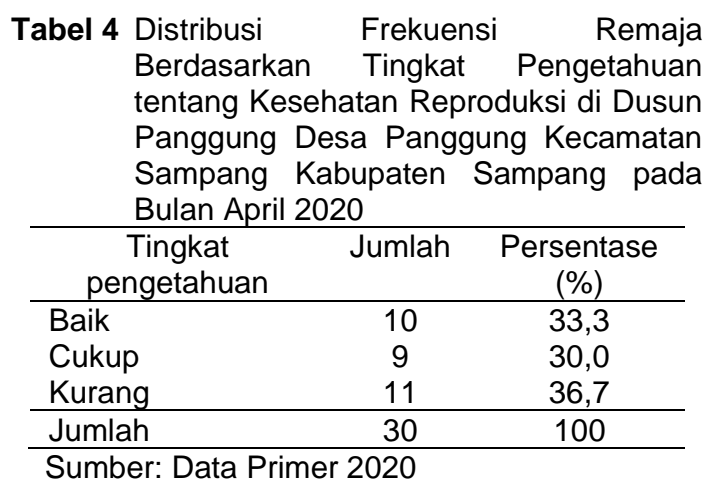


Hubungan antara Pengetahuan Remaja tentang Kesehatan Reproduksi dengan Pernikahan Dini di Desa Panggung Kecamatan Sampang, Sampang

Tabel 4 menunjukkan dari 30 remaja berpengetahuan baik sebanyak 10 remaja $(33,3 \%)$, berpengetahuan cukup 9 remaja (30\%), dan berpengetahuan kurang 11 remaja $(36,7 \%)$.

Remaja dengan pengetahuan kesehatan reproduksi yang baik diharapkan akan terjadi penurunan angka kejadian pernikahan remaja yang pada akhirnya meningkatkan kualitas generasi penerus bangsa Indonesia.

Sesuai dengan penelitian oleh Surya Anita (2020) yang mendapat kesimpulan bahwa perlu adanya sosialisasi yang dilakukan kepada remaja tentang kesehatan reproduksi supaya kejadian pernikahan dini berkurang.

Tabel 5 Distribusi Frekuensi Remaja Berdasarkan Status Pernikahan di Dusun Panggung Desa Panggung Kecamatan Sampang Kabupaten Sampang pada Bulan Februari 2020

Status Pernikahan Jumlah Persentase

\begin{tabular}{ccc} 
& & $(\%)$ \\
\hline Belum Nikah & 18 & 60,0 \\
Nikah Dini & 12 & 40,0 \\
\hline \multicolumn{1}{c}{ Jumlah } & 30 & 100 \\
\hline
\end{tabular}

Sumber: Data Primer 2020

Tabel 5 menggambarkan sebagian besar dari responden belum menikah sebanyak 18 remaja (60\%) dan menikah dini sebanyak 12 remaja (40\%).

Merujuk UU Negara/UU Perkawinan Tahun 1974 bab 11 pasal
7 ayat 1 , maka dapat disimpulkan untuk pernikahan diberikan izin apabila calon mempelai pria minimal berusia 19 tahun, dan calon pengantin wanita usia paling rendah 16 tahun. Jika usia pertama kali menikah masih di bawah umur tersebut di atas, maka dinyatakan sebagai early mariage.

Ketika pernikahan dini terjadi akan banyak efek yang bisa ditimbulkan antara lain: pendidikan, ekonomi, dan kesehatan.

\begin{tabular}{|c|c|c|c|c|c|c|c|}
\hline Tabel 6 & $\begin{array}{l}\text { Dis } \\
\text { Ber } \\
\text { Per } \\
\text { Kes } \\
\text { Per } \\
202\end{array}$ & $\begin{array}{l}\text { ibusi } \\
\text { asar } \\
\text { yetah } \\
\text { hata } \\
\text { ikah }\end{array}$ & $\begin{array}{l}\text { Kan } \\
\text { uan } \\
\text { n Din } \\
\end{array}$ & $\begin{array}{r}\text { reku } \\
\text { Hul } \\
\text { Re } \\
\text { epr } \\
\text { pac }\end{array}$ & $\begin{array}{l}\text { nsi } \\
\text { ungan } \\
\text { naja } \\
\text { duksi } \\
\text { Bulan }\end{array}$ & $\begin{array}{r}\mathrm{Re} \\
\mathrm{a} \\
\text { ter } \\
\mathrm{de} \\
\mathrm{Fek}\end{array}$ & $\begin{array}{l}\text { haja } \\
\text { tara } \\
\text { ang } \\
\text { gan } \\
\text { uari }\end{array}$ \\
\hline & & & atus $\mathrm{P}$ & ernik & han & & \\
\hline Pengetah & uan & & $\begin{array}{l}\text { lum } \\
\text { nikah }\end{array}$ & & $\begin{array}{l}\text { nikah } \\
\text { ini }\end{array}$ & & lah \\
\hline & & $\Sigma$ & $\%$ & $\Sigma$ & $\%$ & $\Sigma$ & $\%$ \\
\hline Kurang & & 4 & 36.4 & 7 & 63.6 & 11 & 100 \\
\hline Cukup & & 4 & 44.4 & 5 & 55.6 & 9 & 100 \\
\hline Baik & & 10 & 100 & 0 & 0 & 10 & 100 \\
\hline Jumlah & & 18 & 60 & 12 & 40 & 30 & 100 \\
\hline Uji Chi-S & uare & & $p: 0.0$ & & $a: 5^{\circ}$ & & \\
\hline
\end{tabular}

Berdasarkan dari hasil uji ChiSquare pada tabel 6 nilai $p=0.006$ sehingga $\mathrm{p}<\mathrm{\alpha}$, maka Ho ditolak sehingga $\mathrm{H}_{1}$ diterima. Kesimpulannya terdapat korelasi antara knowledge remaja mengenai kesehatan reproduksi dengan pernikahan dini.

Sesuai dengan penelitian oleh Tri Indah Septianah, et.al. (2019) yang menyimpulkan adanya 
Hubungan antara Pengetahuan Remaja tentang Kesehatan Reproduksi dengan Pernikahan Dini di Desa Panggung Kecamatan Sampang, Sampang

hubungan antara pengetahuan dengan pernikahan dini.

Dari penelitian juga didapatkan sebanyak 5 remaja $(55,6 \%)$ berpengetahuan cukup tentang kesehatan reproduksi, akan tetapi tetap melakukan pernikahan dini.

Sependapat dengan hasil riset Bhandari, Nub Raj (2019), yang menyatakan kalau masyarakat, tetangga, lingkungan sosial, kerabat dan pemimpin agama merupakan agen utama terjadinya pernikahan dini, dan seseorang yang berada di bangku sekolah dan bisa dikonotasikan punya pengetahuan cukup sampai tinggi tidak bisa lepas dari tradisi pernikahan dini.

\section{Simpulan}

Kesimpulan yang bisa diambil bahwa ada korelasi antara tingkat pengetahuan remaja mengenai kesehatan reproduksi dengan kejadian pernikahan dini di Desa Panggung, Kecamatan Sampang, Kabupaten Sampang

\section{Daftar Pustaka}

Bhandari, N. R. (2019). Early Marriage in Nepal: Prospects for Schoolgirls. Journal of International Women's Studies, 20(3), 88-97.
BPS. Kementerian PPN/Bappenas. (2020). Pencegahan Perkawinan Anak Percepatan Yang Tidak Bisa Ditunda. Jakarta:BPS/Kementerian PPN/Bappenas

Credos Institute. (2017). Situation Analysis of Child Marriage, Teenage Pregnancy and Female General Mutilation in Rembang.

Desiyah, I.W. (2015). Faktor-faktor Yang Berhubungan Terhadap Pernikahan Dini Pada Pasangan Usia Subur di Kecamatan Mapanget, Kota Manado. Jikmu,5, 270-280

https://jatim.bps.go.id. Persentase Perempuan Jawa Timur Usia 10 Tahun Ke Atas Yang Kawin Di Bawah Umur (Kurang dari 17 Tahun) menurut Kabupaten/Kota, 2009-2016, Diunduh tanggal 26 Januari 2020.

https://jatim.bps.go.id. Statistik Pemuda Provinsi Jawa Timur 2018, Diunduh tanggal 29 Januari 2020

https://Repubika.co.id. (2020). Puluhan siswa SMP Sampang DO karena nikah. Diunduh tanggal 26 Januari 2020

https://data.unicef.org

UNICEF Indonesia, Maternal and Newborn Health Disparities. Diunduh tanggal 28 Januari 2020

Hotchkiss, D.R., Godha, D., Gage,A.J., \&Cappa, C. (2016). Risk Associated With The Practice Of Child Mariage Among Roma Girls In Serbia. BMC International Health and Human Rights, 1-10

Kabir, Md. R., Ghosh, S., and Shawly, 
A. (2019). Causes of Early Marriage and Its Effect on Reproductive Health of Young Mothers in Bangladesh. American Journal of Applied Sciences, 289-297

Surya Anita. (2020). Hubungan Sumber Informasi Budaya dan Keluarga Dengan Pernikahan Dini Pada Wanita PUS (Pasangan Usia Subur) di Desa Tembing Kecamatan Percut Sci Tuan Kabupaten Deli Serdang. Vary Midwifery Journal,2, 36-41

Tri Indah Septianah, Tetti Solehati Efri Widianti. (2019). Hubungan Pengetahuan , Tingkat pendidikan, Sumber Informasi, dan Pola Asuh Dengan Pernikahan Dini Pada Wanita. Jurnal Riset Hesti Medan Akper Kesdam I/BB Medan, 4, 73-81

UU Republik Indonesia Nomor 1 Tahun 1974 Tentang Perkawinan 